\title{
A VIOLÊNCIA NAS RELAÇÕES AFETIVAS DE ADOLESCENTES: UMA REVISÃO SISTEMÁTICA
}

VIOLENCE IN ADOLESCENT AFFECTIVE RELATIONSHIPS: A SYSTEMATIC REVIEW

Joice Laine Carvalho ${ }^{1}$, Marjane Bernardy Souza², Natasha Figueiró Souze ${ }^{3}$

RECEBIDO: 07/03/2018 | ACEITO: 07/08/2018

DOI: $10.5902 / 2317175831406$

\section{RESUMO}

O presente estudo trata de uma revisão sistemática com o objetivo de identificar as causas, as formas e o agressor da violência nas relações afetivas de adolescentes. A análise das características fundamentais da violência e da adolescência visam a uma melhor compreensão do tema. O levantamento de dados foi realizado na base do SciELO, com publicação entre 2013 a setembro de 2017. Instituídos os critérios de inclusão (a) artigo empírico; (b) com utilização de instrumentos para coleta de dados; (c) que assinalem as causas, as formas e o agressor, assim oito estudos foram analisados na íntegra. Essas publicações utilizaram como instrumentos Questionários sociodemográficos fechados de autopreenchimento, Escala CADRI (Conflict in Adolescent Dating Relationships Inventory), subescala Conflict Tactics Scale, Entrevista individual e Grupo focal. Os resultados apontam que a violência nas relações afetivas entre adolescentes sofre incontestável influência de vivências agressivas prévias, normalmente, ligadas a pais, irmãos, amigos e relacionamentos anteriores. Nos artigos analisados, não há concordância absoluta acerca da prevalência de gênero do agressor, contudo, os autores entendem que a violência reflete um padrão de continuidade do comportamento agressivo. Ainda que aconteçam diversas formas de violência (sexual, física, verbal, psicológica), concluiu-se que, em diversas oportunidades, todas estão intrinsecamente ligadas à violência de cunho psicológico. Portanto, para eliminar a prática da violência e a sua reprodução, deverão ser objetos de questionamento e de constante reflexão, determinados padrões de comportamento instituídos em nossa sociedade.

Palavras-chave: Violência. Adolescência. Namoro.

\footnotetext{
${ }^{1}$ Graduanda do Curso de Psicologia da Universidade Luterana do Brasil - Campus São Jerônimo

2 Gruaduada em Psicologia-Bachalerado pela Universidade do Vale do Rio dos Sinos (UNISINOS), Psicologia-Licenciatura pela Universidade Federal do Rio Grande do Sul (UFRGS), especialização em Aconselhamento das Relações Familiares pela Pontifícia Universidade Católica do Rio Grande do Sul (PUCRS) e Mestre em Família e Sistemas Sociais pelo Instituto Superior Miguel Torga - Coimbra-Portugal (ISMT-2004), especialista em Psicologia no Trânsito (CFP) e especialista em Psicologia Jurídica (CFP). Perita em Avaliação Psicológica no Departamento de Trânsito - DETRAN/RS

${ }^{3}$ Graduanda do Curso de Psicologia da Universidade Luterana do Brasil - Campus Canoas
} 
JOICE LAINE CARVALHO, MARJANE BERNARDY SOUZA, NATASHA FIGUEIRÓ SOUZE

\begin{abstract}
The presente study deals with a systematic review aiming to identify the causes, the forms and the agressor of the violence on the teenagers's datings. The analysis of the fundamental characteristics of violence and adolescence aim at a better understanding of the theme. The data collection was carried out at the SciELO base (publications between 2013 and september 2017). Instituted the inclusion criteria: (a) empirical article; (b) using instruments for data collection; (c) that indicate the causes, the forms and the agressor, eight studies have been analyzed in the whole. These publications used as instruments: Self-filling closed sociodemographic quetionnaires, CADRI (Conflict in Adolescent Dating Relationships Inventory, Conflict Tactics Scale subscale, individual interview and Focus group. The results indicate that violence on the teenagers's datings suffers the undeniable influence of previous aggressive experiences usually linked to parents, siblings, friends and previous relationships. In the analyzed articles, there is no absolute agreement about the gender prevalence of the aggressor, however the authors understand that violence reflects a pattern of continuity of aggressive behavior. Although there are several forms of violence (sexual, physical, verbal, psychological), it has been concluded that, on several occasions, all are intrinsically linked to psychological violence. Therefore, to eliminate the practice of violence and its reproduction, certain patterns of behavior instituted in our society should be objects of questioning and constant reflection.
\end{abstract}

Keywords: Violence. Adolescence. Dating.

\title{
1 Introdução
}

A violência no namoro de adolescentes é um assunto ainda novo nas bibliografias científicas, sendo um fenômeno de suma importância. Em razão disso, mostra-se relevante aprofundar o conhecimento, pois possibilita a análise das situações da agressão, geralmente provindas da infância, além das repercussões na fase da adolescência, especialmente no âmbito das relações afetivas.

Devido à larga abrangência do tema, que pode ser analisado a partir de diversas perspectivas, o presente estudo tem por objetivos: identificar as causas, as formas e o agressor da violência no namoro de adolescentes.

A violência exterioriza-se, conforme Camargo (2017), por meio de atrocidade, da opressão e do abuso da força. Sucede do constrangimento exercido sobre alguma pessoa para obrigá-la a fazer ou deixar de fazer um ato qualquer.

$\mathrm{Na}$ fase adolescente que Abreu e Souza (2017) referem as mudanças profundas, exageros e carências sob diversos pontos de vista. A violência no namoro de adolescentes é considerada um problema de saúde pública que, de acordo com Oliveira et al (2013), pode reproduzir-se em padrão de resolução de conflitos íntimos na vida adulta.

Assim, em razão da adolescência ser o período relevante, no qual se organiza as bases necessárias para a construção de relações saudáveis e o bemestar geralao longo da vida do adolescente, é importante oportunizar que esses jovens possam usufruir de relacionamentos livres de violência \,investindo em estratégias de prevenção e promoção para minimizar tais fatos. 


\section{A Violência}

Segundo o Ministério da Saúde (2005), nos estudos científicos da área da saúde, há no mínimo três correntes que procuram explicar a violência: a primeira afirma que é resultante de necessidades biológicas; a segunda defende que decorre, exclusivamente, do arbítrio dos sujeitos, ou seja, que os resultados socialmente visíveis dependem da soma dos comportamentos individuais, como se fosse resultante de doença mental ou estivesse vinculada a determinadas concepções morais e religiosas; a terceira trata o âmbito social como ambiente dominante na produção e vitimização da violência, onde tomam corpo e se transformam os fatores biológicos e emocionais.

A violência expressa-se, segundo Camargo (2017), por meio da atrocidade, da opressão e do abuso da força. Decorre do constrangimento exercido sobre alguma pessoa para obrigá-la a fazer ou deixar de fazer um ato qualquer. Várias causas colaboram para aumentar a violência, tais como: a miséria, a fome, o desemprego. Mostra-se em diversas configurações e pode ser constatada, especialmente, em grupos considerados vulneráveis, sendo classificada como de cunho sexual, político, psicológico, físico, verbal, dentre outros. Em seus mais variados contornos, é um fato histórico na constituição da sociedade brasileira.

Alguns jovens e suas famílias, Moura et al (2015) relata que, às vezes são atingidos por vários tipos de violência, osquais não afetam exclusivamente suas vidas, mas acabam modificando as vivências comunitárias, a ocupação socioespacial dos territórios a as dinâmicas da cidade, além de representar infração aos direitos fundamentais, potencializa efeitos intergeracionais de agressão.

A violência nas relações afetivas de namoro ou do "ficar" é um problema grave que resulta em vários efeitos negativos, e Minayo et al (2011) aponta que deve ser compreendida no contexto da violência social, levando em conta os aspectos históricos e sociais, sobretudo os referentes às relações de gênero. A violência pode ocorrer entre jovens, independe qual a classe social, média ou popular, se esses frequentam escolas públicas ou particulares, o fenômeno perpassa todos os grupos e segmentos e se entranha neles. Para muitos jovens a base da violência relacional que praticam foi estruturada e organizada na infância e ativada e potencializada na adolescência.

Em circunstâncias de violências conjugais, as estatísticas atestam que há maior ocorrência de violência do homem contra mulher,. Já na adolescência, ambos os sexos são vítimas ou perpetradores, pelo fato de ser uma fase de onde a relação se mantém com menos compromisso e menor cobrança. Ainda sobre essa fase, Minayo et al (2011) refere ao fato de não haver dependência econômica, filhos, ou bens compartilhados que poderiam alegar a continuidade da relação diante a violência. 


\subsection{A adolescência e a condição juvenil}

Conforme o Estatuto da Criança e do Adolescente (ECA, 2014), no artigo $2^{\circ}$, caput, a adolescência é definida dos 12 aos 18 anos de idade, sendo prevista - em seu parágrafo único - nos casos expressamente consignados em lei, a excepcionalidade às pessoas de 18 a 21 anos. Compreende, assim, o período descrito como um momento primordial, em que deixa de ser a criança para se apropriar de seus aspectos de personalidade e vivências no meio biopsicossocial.

Abreu e Souza (2017) mencionam as mudanças profundas, exageros e carências sob diversos pontos de vista. Nesta fase, o sujeito vê-se frente a um corpo que está mudando lenta e estranhamente: não quer mais ser criança e ignora a proteção da família, porém, tudo não passa de uma revolução biológica e psíquica que é natural nesse período do desenvolvimento e que resulta em um comportamento oscilante.

$\mathrm{Na}$ apresentação ao mundo, Minayo et al (2011) expõe que o adolescente corre o risco de rejeitar e renegar os valores tradicionais sem, pelo menos, compreendê-los suficientemente, o que explica o fato de nem sempre assumirem atitudes transformadoras e libertadoras.

O adolescente passa por desequilíbrios e instabilidades extremas, que é uma condição perturbada e perturbadora para o mundo adulto. Contudo, para Aberastury et al (1990), são absolutamente necessários para estabelecer a sua identidade como objetivo fundamental deste momento da vida.

De acordo com os autores anteriormente citados, Minayo et al (2011) e Aberastury et al (1990), é o período que flutua entre uma dependência e uma independência proeminente, sendo que somente a maturidade, futuramente, proporcionará a aceitação da independência dentro de um limite de necessária dependência. Para que esse processo ocorra, a maturidade biológica deve estar acompanhada da maturidade afetiva e intelectual, que permite a entrada do jovem no mundo adulto munido de um sistema de valores e de uma ideologia que confronta com a de seu meio, na qual a rejeição a determinadas situações cumpre-se em uma crítica construtiva.

O termo "condição juvenil" é utilizado por vários autores, inclusive Minayo et al (2011), para expressar o grupo etário que vai da pré-adolescência até a juventude. É delineado pelo fato de os adolescentes estarem vivendo um período específico do ciclo de vida, em um marcado momento histórico e peculiar cenário cultural, em que completam as suas formações física, intelectual, psíquica, social e cultural. Vivenciam, durante a "condição juvenil", a passagem da situação de dependência para a de autonomia em relação à família de origem, na qual thes é concedido pela sociedade um prazo - denominado moratória social - que consiste no tempo livre de menor exigência de obrigações adultas, que perdura enquanto completam seus estudos e alcançam a maturidade social. 
A VIOLÊNCIA NAS RELAÇÕES AFETIVAS DE ADOLESCENTES: UMA REVISÃO SISTEMÁTICA

Notadamente, na fase da "condição juvenil", ocorrem os primeiros relacionamentos afetivos, com todas as complexidades das relações afetuosas, que deverão ser somadas às características inerentes ao referido período de desenvolvimento. Tal combinação, por vezes, resulta em uma conjuntura tumultuada, desencadeando em violência.

\subsection{A Violência e o namoro da adolescência}

Com a modernização, as relações afetivas, as experimentações e a variedade de formas de relacionamentos, na fase da juventude, não se restringem ao namoro. Conforme Minayo et al (2011), a partir da década de 1980, a expressão "ficar" é bem comum e usada entre os jovens, caracterizando uma etapa de atração sem maiores compromissos.

As peculiaridades do teste, do "ficar", identificam-se com a juventude, época da vida em que a sexualidade está no auge e à flor da pele, e os papéis sexuais definindo-se. Nessa expectativa, a vida amorosa e sexual está inserida em um contexto de busca de identidade e de autonomia, e a escolha dos parceiros amorosos é uma forma de aprendizado da sexualidade não restrita à genitalidade (MINAYO, 2011).

Por sua vez, no namoro, Minayo et al (2011), refere que a percepção sobre o tipo de relacionamento com o outro é diferente, pois evidencia a entrada do jovem na cena dos adultos, principalmente, pela inclusão do relacionamento no círculo familiar.

Diversos estudos demonstram as repercussões negativas na saúde dos adolescentes que experimentaram situações de violência no namoro, pois tendem a apresentar sintomas de depressão e ansiedade, a ter envolvimento com tabaco, drogas e álcool, além de comportamentos antissociais e pensamentos suicidas (Foshere, Reyes,Gottfredson, Chang \& Ennet, 2013).

A violência nos namoros de adolescentes é cogitada como um problema de saúde pública, de acordo com Oliveira et al (2013), já que sua ação pode reproduzir-se em padrão de resolução de conflitos íntimos na vida adulta. A violência física e sexual produz efeitos mais visíveis, ao passo que a violência psicológica só é aparente quando expressa em comportamentos apresentados pelas vítimas com o passar do tempo.

Uma pesquisa executada por Barreira, et al (2013), no Brasil no ano de 2008, com adolescentes matriculados em escolas públicas e particulares, com idades entre 15 e 19 anos, apontou - nas relações de namoro - uma predominância da violência física de 19,9\%; violência psicológica de 82,8\%; ambas de $18,9 \%$.

Vivenciar a violência na relação amorosa, na adolescência, para Oliveira et. al (2013), é o reflexo de abusos sofridos pelos adolescentes ainda na infância - em suas famílias de origem - e que se repetirá nas famílias que os próprios venham a construir na vida adulta. 
Segundo Leitão et al (2013), a violência nas relações de namoro sobrevém tanto no sexo masculino contra o sexo feminino, quanto no feminino contra o masculino, bem como nas relações entre pessoas do mesmo sexo. Afeta e percorre todos os grupos étnicos, culturais, níveis socioeconômicos ou educativos, possuindo raízes históricas e culturais. A cartilha "Impacto da Violência na Saúde dos Brasileiros", do Ministério da Saúde (2005), afirma que a violência traz prejuízos individuais e coletivos como danos, lesões, traumas e mortes.

Utilizando dados de uma pesquisa realizada entre 2007 e 2009, por Oliveira et. al (2013), que investigou a prevalência da violência no namoro entre adolescentes de 15 a 19 anos de idade, verificou-se a perpetração de violência psicológica no relacionamento afetivo-sexual atual de adolescentes do sexo masculino e feminino e sua relação com violência psicológica vivenciada em outros contextos de suas vidas, tais quais: família, amigos e parceiros anteriores. Os resultados destacam que o aumento do número de eventos de violência psicológica - cometidas pelos adolescentes em seus relacionamentos íntimos - está relacionado à agressão verbal da mãe e do pai; à vivência de violência psicológica entre pais, irmãos, amigos; a namoros anteriores. Em sendo assim, reforça a noção de circularidade da violência psicológica, nos diversos contextos de socialização do adolescente e, igualmente, a continuidade do comportamento agressivo em outras relações.

Conforme Beserra et al (2015), uma pesquisa realizada sobre Prevalência de Violência no Namoro entre Adolescentes de Escola Pública de Recife/PE - Brasil 2014 apresentou o predomínio da violência no namoro de 19,2\%, averiguando associações significativas entre o sexo e as questões vítima e agressor, e observando mais meninas agressoras (14,3\%). Após a agressão, $40 \%$ responderam que não sentiam nada, 28\% acharam normal, $40 \%$ não fizeram nada a respeito do assunto e $36 \%$ terminaram a relação afetiva

No artigo Violência Física praticada por ciúmes no Namoro de Adolescentes: Um recorte de Gênero em Dez Capitais Brasileiras, Oliveira et al (2016) cita que os adolescentes revelam o ciúme e a infidelidade como justificativa para as agressões físicas entre namorados, respaldando-se em normas de gênero que se expressam na violência como construção da masculinidade, na banalização da violência física feminina e na violência física contra meninas cometidas por um e outro sexo.

\section{Método}

Pesquisa exploratória bibliográfica elaborada. Utilizou-se uma revisão sistemática que, de acordo com Koller et al (2014), fundamenta-se no processo a reunião, avaliação crítica e sintética de resultados de múltiplos estudos. É o método que possibilita maximizar o potencial de uma busca, sendo possível encontrar um maior número de resultados de maneira organizada. 


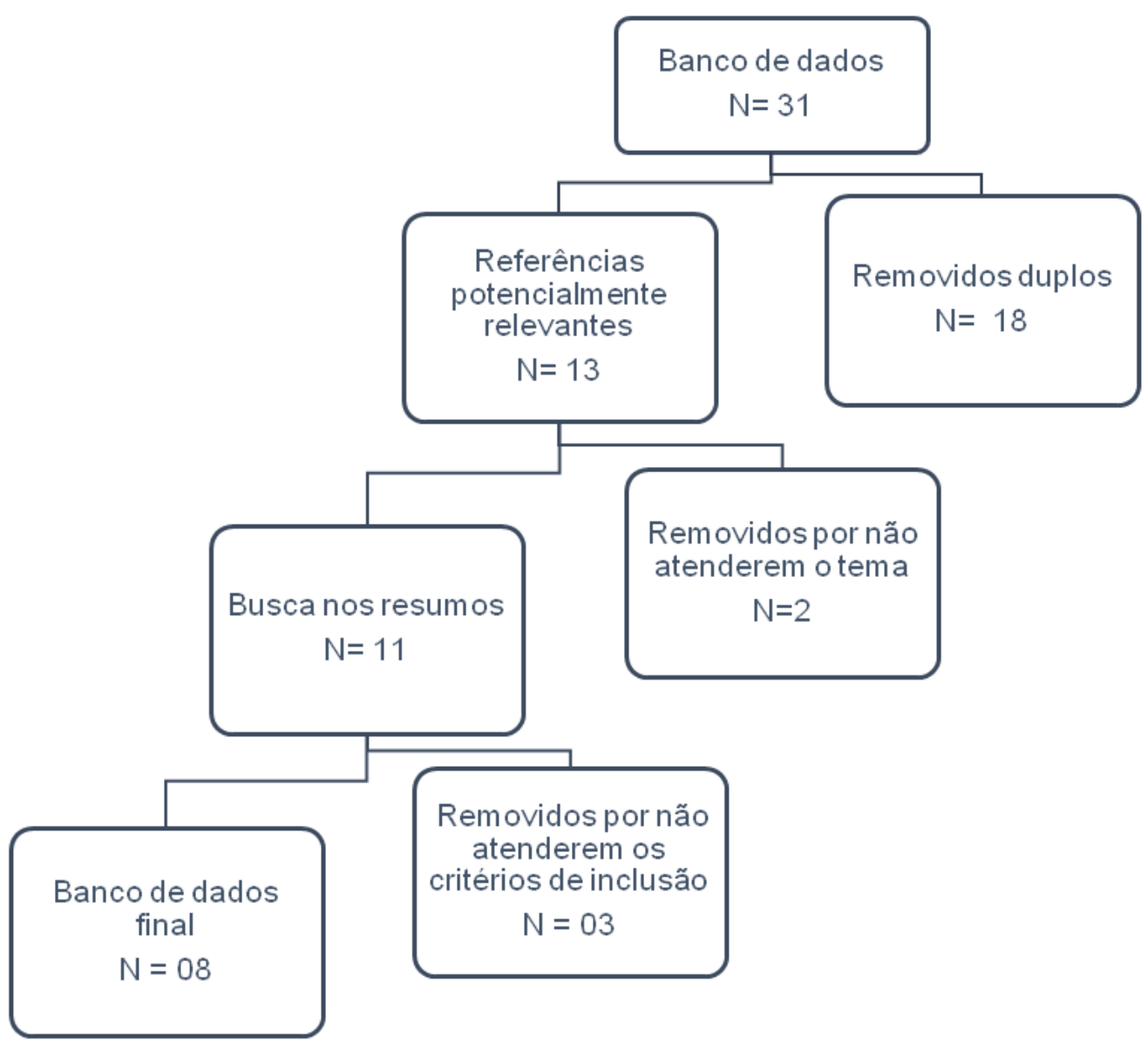

Fonte: Elaborada pelo autor.

\subsection{Procedimentos para Coleta de Dados}

Os dados para a pesquisa foram coletados através de artigos selecionados na base de dados eletrônica SciELO (Scientific Eleletronic Libray Online). Para a busca dos artigos, foram utilizados alguns recursos disponíveis na base de dados, o que possibilitou maior exploração dos campos de pesquisa. As estratégias de busca foram definidas pelas palavras-chaves: namoro, violência e adolescência, com as seguintes combinações: Namoro - Violência - Adolescência/Namoro - Violência/ Adolescência - Namoro; pelo idioma em português e pelo período da publicação de 2013 a setembro de 2017.

Ao todo, foram encontrados 31 artigos na base de dados, 18 artigos estavam repetidos. Restando 13 artigos, dois não atenderam o tema, portanto foram removidos, restando 11.

Os resumos desses 11 artigos restantes foram lidos para avaliação de inclusão, considerando-se os seguintes critérios: (a) artigo empírico; (b) utilização de instrumentos para a coleta de dados; (c) apontamento da 
violência no namoro de adolescentes. Destes, três artigos não preencheram os critérios de inclusão, em consequência, foram removidos.

O banco de dados final constou, portanto, de oito artigos, que foram lidos na íntegra por atenderem os critérios de inclusão estabelecidas.

\subsection{Procedimentos para Tabulação}

Para a análise e integração dos dados, foi utilizada uma ficha de avaliação com o propósito de identificar e relacionar as informações dos estudos lidos na íntegra. Os resultados das pesquisas podem ser demonstrados e dispostos conforme Tabela 1.

\section{Apresentação e Discussão dos Resultados}

A Tabela 1 refere a enumeração dos artigos, o ano de publicação, os dados empíricos e os instrumentos utilizados para a pesquisa.

\subsection{Ano de publicação}

Artigos publicados entre 2013 até setembro de 2017, que atenderam os objetivos da pesquisa e os critérios de inclusão.

\subsection{Dados empíricos}

Os artigos enumerados contam com um total de 12.379 jovens testados e entrevistados como vítimas ou perpetradores da violência no namoro de adolescentes. Os dados foram coletados em escolas, públicas e privadas, de onze cidades do Brasil e quatro distritos da Região Central de Portugal. 
A VIOLÊNCIA NAS RELAÇÕES AFETIVAS DE ADOLESCENTES: UMA REVISÃO SISTEMÁTICA

Tabela 1 - Dados utilizados para a pesquisa.

\begin{tabular}{|c|c|c|c|c|}
\hline $\mathrm{N}^{\circ}$ & Artigo/Autor & Ano & Empírico/ no & Instrumentos \\
\hline 01 & $\begin{array}{l}\text { Violência Física Perpetrada por Ciúmes no Namoro de } \\
\text { Adolescentes: Um Recorte de Gênero em Dez Capitais } \\
\text { Brasileiras } \\
\text { Queiti Batista Moreira Oliveira; Simone Gonçalves de } \\
\text { Assis; Kathie Njaine; Thiago de Oliveira Pires }\end{array}$ & 2016 & $\begin{array}{l}3.205 \text { adolescentes: } 15 \text { a } \\
19 \text { anos }\end{array}$ & $\begin{array}{l}\text { - Questionário } \\
\text { - Escala CADRI (Conflict } \\
\text { in Adolescent Dating } \\
\text { Relationships Inventory) }\end{array}$ \\
\hline 02 & $\begin{array}{l}\text { Prevalência e Características da Violência no Namoro } \\
\text { entre Adolescentes Escolares de Portugal } \\
\text { Maraia Aparecida Beserra; Maria Neto da Cruz Leitão; } \\
\text { Joana Alice da Silva Amaro de Oliveira Fabião; Maria dos } \\
\text { Anjos Coelho Rodrigues Dixe; Cristina Maria Figueira } \\
\text { Veríssimo; Maria das Graças Ferriani }\end{array}$ & 2016 & $\begin{array}{l}\text { 4.158 estudantes: } \\
14 \text { a } 19 \text { anos }\end{array}$ & $\begin{array}{l}\text { - Questionário } \\
\text { Sociodemográfico } \\
\text { - Questionário sobre } \\
\text { o tempo de namoro e } \\
\text { condições que avaliam o } \\
\text { comportamento ocorrido } \\
\text { no contexto das relações } \\
\text { amorosas }\end{array}$ \\
\hline 03 & $\begin{array}{l}\text { Violência por Parceiro Íntimo na Adolescência: Uma } \\
\text { Análise de Gênero e Geração } \\
\text { Bianca de Cássia Alvarez Brancaglioni; Rosa Maria Godoy } \\
\text { Serpa da Fonseca }\end{array}$ & 2016 & $\begin{array}{l}111 \text { adolescentes: } 15 \text { a } \\
19 \text { anos }\end{array}$ & - Escala CADRI \\
\hline 04 & $\begin{array}{l}\text { Violências Percebidas por Homens Adolescentes na } \\
\text { Interação Afetivo-sexual em Dez Cidades Brasileiras } \\
\text { Fátima Cecchetto; Queiti Batista Moreira Oliveira; Kathie } \\
\text { Njaine; Maria Cecília de Souza Minayo }\end{array}$ & 2016 & $\begin{array}{l}257 \text { estudantes do sexo } \\
\text { masculino do } 2^{\circ} \text { ano do } \\
\text { Ensino Médio }\end{array}$ & $\begin{array}{l}\text { - Entrevista Individual } \\
\text { - Grupo focal }\end{array}$ \\
\hline 05 & $\begin{array}{l}\text { Prevalência de Violência no Namoro entre Adolescentes } \\
\text { de Escolas Públicas de Recife/ PE - Brasil } \\
\text { Maria Aparecida Beserra; Maria Neto da Cruz Leitão; } \\
\text { Maria Isabel Domingues Fernandes; Liliana Scatena; } \\
\text { Telma Sofia dos Santos Vidinha; Lygia Maria Pereira da } \\
\text { Silva; Maraia das Graças de Carvalho Ferriane }\end{array}$ & 2015 & $\begin{array}{l}4.905 \text { estudantes de } \\
\text { ambos os sexos: } 12 \text { a } 18 \\
\text { anos }\end{array}$ & $\begin{array}{l}\text { - Questionários: Global } \\
\text { School -based Student } \\
\text { Healtb Survey e Violência na } \\
\text { Escola. }\end{array}$ \\
\hline 06 & $\begin{array}{l}\text { Direcionalidade da Violência Física e Psicológica no } \\
\text { Namoro entre Adolescentes do Recife, Brasil } \\
\text { Alice Keiiy Barreira; Maria Luiza Carvalho de Lima; Marc } \\
\text { Bigras; Kathie Njaine; Simone Gonçalves Assis }\end{array}$ & 2014 & $\begin{array}{l}408 \text { estudantes do } 2^{\circ} \text { ano } \\
\text { do Ensino Médio }\end{array}$ & $\begin{array}{l}\text { - Questionário } \\
\text { - Escala CADRI }\end{array}$ \\
\hline 07 & $\begin{array}{l}\text { Namoro na Adolescência no Brasil: Circularidade } \\
\text { da Violência Psicológica nos Diferentes Contextos } \\
\text { Relacionais } \\
\text { Queiti Batista Moreira Oliveira; Simone Gonçalves de } \\
\text { Assis; Kathie Njaine; Thiago Oliveira Pires }\end{array}$ & 2013 & $\begin{array}{l}3.205 \text { adolescentes de } 15 \\
\text { a } 19 \text { anos }\end{array}$ & $\begin{array}{l}\text { - Questionário } \\
\text { - Escala CADRI }\end{array}$ \\
\hline 08 & $\begin{array}{l}\text { Coocorrência de Violência Física e Psicológica entre } \\
\text { Adolescentes Namorados do Recife, Brasil: Prevalência e } \\
\text { Fatores Associados } \\
\text { Alice Kelly Barreira; Maria Luiza Carvalho de Lima; } \\
\text { Joviana Quintes Avanci }\end{array}$ & 2013 & $\begin{array}{l}302 \text { adolescentes com } \\
\text { idade entre } 15 \text { e } 19 \text { anos } \\
\text { do } 2^{\circ} \text { ano do Ensino } \\
\text { Médio }\end{array}$ & $\begin{array}{l}\text { - Questionário fechado de } \\
\text { autopreenchimento } \\
\text { - Escala CADRI }\end{array}$ \\
\hline
\end{tabular}




\subsection{Instrumentos}

Como instrumentos, foram usados questionários fechado de autopreenchimento, composto por várias perguntas, incluindo características sociodemográficas e quesitos sobre a aceitação da violência no namoro. Utilizou-se também: a) a escala CADRI (Conflict in Adolescent Dating Relationships Inventory), criada por Wolfe et al. e adaptada e validada para o português por Minayo, Assis e Njaine (2003), que afere a vitimização e perpetração de violência física, sexual e psicológica na relação de intimidade ; b) a Conflict Tactics Scale, que afere a violência familiar dos pais contra os filhos; e c) a sub escala com 6 itens (validada para a população brasileira), que avalia a agressão verbal praticada pelo pai e pela mãe sobre o (a) adolescente entrevistado(a), além de Entrevista individual e Grupo focal

\subsection{Causas - formas - agressor}

\subsubsection{Causas da violência entre namorados}

As causas da violência são fatores que certificam e justificam as formas de agressão no namoro de adolescentes. O ciúme e a infidelidade, por sua vez, são enfatizados como elementos que evidenciam as razões para agressões físicas entre namorados, tanto por parte dos meninos como das meninas.

Tabela 2 - Causas - Formas - Agressor

\begin{tabular}{|l|l|l|l|l|}
\hline $\mathbf{N}^{\mathbf{0}}$ & ARTIGO/autor & CAUSAS & FORMAS & AGRESSOR \\
\hline 01 & $\begin{array}{l}\text { Violência Física Perpetrada por Ciúmes no Namoro de } \\
\text { Adolescentes: Um recorte de Gênero em Dez Capitais } \\
\text { Brasileiras } \\
\text { Queiti Batista Moreira de Oliveira; Simone Gonçalves de } \\
\text { Assis; Kathie Njaine; Thiago de Oliveira Pires }\end{array}$ & $\begin{array}{l}\text { Ciúme e } \\
\text { Infidelidade }\end{array}$ & Física & Ambos \\
\hline 02 & $\begin{array}{l}\text { Prevalência e Características da Violência no Namoro } \\
\text { entre Adolescentes de Portugal } \\
\text { Maria Aparecida Beserra; Maria Neto da Cruz Leitão; } \\
\text { Joana Alice da Silva Amaro de Oliveira Fabião; Maria dos } \\
\text { Anjos Coelho Rodrigues Dixe; Cristina Maria Figueira } \\
\text { Veríssimo; Maria das Graças Ferriani }\end{array}$ & $\begin{array}{l}\text { Tempo de } \\
\text { Namoro }\end{array}$ & $\begin{array}{l}\text { Física } \\
\text { Psicológica } \\
\text { Sexual }\end{array}$ & Ambos \\
\hline 03 & $\begin{array}{l}\text { Violência por Parceiros Íntimo na Adolescência: Uma } \\
\text { Análise de Gênero e Geração } \\
\text { Bianca de Cássia Alvarez Brancaglioni; Rosa Maria } \\
\text { Godoy Serpa da Fonseca }\end{array}$ & Autodefesa & $\begin{array}{l}\text { Verbal } \\
\text { Emocional } \\
\text { Psicológica }\end{array}$ & Feminino \\
\hline 04 & $\begin{array}{l}\text { Violências Percebidas por Homens Adolescentes na } \\
\text { Interação Afetivo-Sexual em Dez Cidades Brasileiras } \\
\text { Fátima Cechetto; Queiti Batista Moreira Oliveira; Kathie } \\
\text { Njaine; Maria Cecília Minayo }\end{array}$ & Ciúme & Masculino \\
\hline
\end{tabular}




\begin{tabular}{|c|c|c|c|c|}
\hline $\mathrm{N}^{\circ}$ & ARTIGO/autor & CAUSAS & FORMAS & AGRESSOR \\
\hline 05 & $\begin{array}{l}\text { Prevalência de Violência no Namoro entre Adolescentes } \\
\text { de Escola Públicas de Recife/PE - Brasil } \\
\text { Maria Aparecida Beserra; Maria Neto da Cruz Leitão; } \\
\text { Maria Isabel Domingues Fernandes; Liliana Scatena; } \\
\text { Telma Sofia dos Santos Vidinha; Lygia Maria Pereira da } \\
\text { Silva; Maria das Graças de Carvalho Ferriane }\end{array}$ & & Verbal & Feminino \\
\hline 06 & $\begin{array}{l}\text { Direcionalidade da Violência Física e Psicológica no } \\
\text { Namoro entre Adolescentes do Recife, Brasil } \\
\text { Alice Kelly Brreira; Maria Luiza Carvalho de Lima; Marc } \\
\text { Bigras; Kathie Njaine; Simone Gonçalves Assis }\end{array}$ & & $\begin{array}{l}\text { Física } \\
\text { Psicológica }\end{array}$ & Bidirecionalidade \\
\hline 07 & $\begin{array}{l}\text { Namoro na Adolescência no Brasil: Circularidade } \\
\text { da Violência Psicológica nos Diferentes Contextos } \\
\text { Relacionais } \\
\\
\text { Queiti Batista Moreira Oliveira; Simone Gonçalves de } \\
\text { Assis; Kathie Njaine; Thiago Oliveira Pires }\end{array}$ & & Psicológica & \\
\hline 08 & $\begin{array}{l}\text { Coocorrência de Violência Física e Psicológica entre } \\
\text { Adolescentes Namorados do Recife, Brasil: Prevalência e } \\
\text { Fatores Associados } \\
\text { Alice Kelly Barreira; Maria Luiza Carvalho de Lima; } \\
\text { Joviana Quintes Avanci }\end{array}$ & $\begin{array}{l}\text { Extrema } \\
\text { Violência } \\
\text { Urbana }\end{array}$ & Psicológica & \\
\hline
\end{tabular}

Fonte: Elaborada pelo autor.

Como causa da violência, nos artigos 01 e 04, o sentimento de ciúmes provocado pela infidelidade, real ou suposta, apresenta-se como um fator importante entre adolescentes, que desencadeia agressões e explosões de raiva que acabam por gerar danos aos parceiros, sobretudo quando se manifesta como um alicerce para a construção da masculinidade, que embora seja um sentimento de superioridade de traços patriarcais, ainda se encontra presente na sociedade atual. O jovem acredita que tem poder sobre a parceira, considerando a infidelidade masculina normal e, ainda, entendendo que as crises de ciúme são manifestação de amor, banaliza a violência, pois passa a aceitar com naturalidade a agressão tanto o que sofre quanto o que comete a agressão, Favero (210) destaca como patriarcado contemporâneo.

No tocante à questão de gênero, verifica-se uma maior aceitação/legitimidade da agressão feminina e maior condenação da agressão masculina. Ademais, as ofensas físicas praticadas por meninas foram consideradas de menor potencial ofensivo e danoso. Como dizem Abreu e Souza (2017), adolescência é uma fase de revolução biológica e psíquica que é natural neste período do desenvolvimento e que resulta em um comportamento oscilante, de desequilíbrios e instabilidades extremos, que Aberastury et al (1990) reforça ser absolutamente necessário para estabelecer a identidade como objetivo fundamental deste momento da vida.

Atribui à violência o artigo 02 ao tempo de namoro: quanto maior o tempo da relação, maior a perpetração e vitimização feminina, apresentandose o sexo masculino apenas na condição de perpetrador. Em Portugal, 5,9\% dos 1.268 estudantes adolescentes relataram envolvimento em situação de violência no namoro, mostrando-se comum a utilização de bofetadas, 
empurrões e pontapés, dentre outros. No início do namoro, adolescentes levam em conta a necessidade de conquistar o novo amor, o carinho e atenção é primordial, já - com o passar do tempo - a mistura de amor e violência faz parte da relação com agressões físicas e psicológicas.

A menina pode perpetrar a agressão como atitude de autodefesa, que é capaz de estar vinculada a agressões sofridas na família, muitas vezes, até em público, conforme as causas do artigo 03. Comporta-se, muitas vezes, nas relações de namoro, de maneira agressiva com intuito de se defender e de não ser subjugada, tende a gritar com o parceiro, mesmo tendo um impacto negativo. Essa reação não pertence somente a um grupo de vulnerabilidade social, é também determinada pela construção histórica e social que precisa ser compreendida.

Como causa da alta prevalência de violência no namoro de adolescentes na cidade de Recife, o artigo 08 cita a extrema violência urbana. Embora outros elementos estejam associados, como a agressão física e psicológica da violência doméstica entre pai e mãe, e entre irmãos. A violência física é o que deixa marcas visíveis, mas a violência psicológica prevalece muito mais. Cria-se aí um círculo de violência, que inicia no lar, saindo para o meio social de amigos e namorados e retornando novamente ao lar com outras experiências de violência.

\subsubsection{Formas de violência}

A forma de violência praticada no namoro dos adolescentes que os artigos 1 e 6 relatam reporta-se à cultura patriarcal, às questões de gênero que permeiam a violência física cometida no namoro, que estão frequentemente presente em muitos lares. A cultura patriarcal-que, nas causas, foi um dos fatores da violência no namoro - agora aparece como forma de bidirecionalidade, na qual ambos os parceiros são agressores tanto na forma física como psicológica.

Na violência psicológica os maiores perpetradores são do sexo masculino, pois adotam um comportamento controlador por meio de gritos, ameaças e perseguição, a fim de provocar medo. Há o momento que ambos os sexos perpetrem violência física, com simetria entre o par tanto um como o outro. É uma situação complicada e que para romper esta dinâmica relacional é preciso intervir em conjunto com casal, e não individualmente.

O artigo 03 e 05 aponta como forma de violência, no namoro de adolescente, excepcionalidade de dissociação entre a violência verbal/emocional e a violência psicológica. Visto que é muito raro não haver violência psicológica em conjunto com a violência física e sexual para quem é vítima do agressor, embora haja mutualidade das agressões.

Por sua vez, o artigo 06 e 07 também menciona a forma de violência física e psicológica cometida por ambos os sexos, e refere do mesmo modo a necessidade de uma intervenção com o casal para prevenir futuras violências no relacionamento adulto. 
A violência psicológica praticada por ambos os sexos, nos relacionamentos íntimos, que refere o artigo 07, está relacionada às agressões verbais da mãe e do pai, bem como à frequente vivência de violência psicológica entre pais, irmãos, amigos e de namoros anteriores. Reforça-se assim, a noção de circularidade da violência psicológica nos diversos contextos de socialização do adolescente, configurando a continuidade do comportamento agressivo nas diversas relações. A criança vivencia as agressões desde muito pequena e, quando chega na adolescência, nos primeiros relacionamentos amorosos, considera que tudo deve ser solucionado através da violência, pois o diálogo ou uma estratégia saudável para ajudar a solucionar um desentendimento nem sempre foi aprendido. Isso é o que Minayo et al (2011) chama de fenômeno de violência cultural, por se tratar de algo naturalizado e internalizado no dia a dia de uma sociedade.

Por fim, o artigo 08 mostra a forma de violência no namoro de adolescente por meio de uma observação: os adolescentes que vivenciam violência na comunidade apresentam quase quatro vezes mais chances de cometer violência psicológica no namoro. Isto vem ao encontro da alta prevalência de violência no namoro observada na cidade de Recife, que apresenta extrema violência urbana, o qual faz uma ligação com os outros artigos, no que refere à coocorrência da violência física e psicológica que, quando perpetrada pelo pai, é a mais determinante na construção do sujeito.

\subsubsection{Agressor}

Ambos os sexos são os agressores, é o que os artigos 01 e 02 relatam. Assim, evidencia-se o quanto ainda persistem os valores tradicionais que transferem a violência vivenciada no lar com pais e irmãos; os adolescentes passam a usar nas relações amorosas. Assim expressa a coexistência da violência entre visões tradicionais e visões mais igualitárias e simétricas, o que faz parte da mudança cultural e dos valores sociais. Em conjunto com o artigo 03, no qual as meninas são as agressoras como uma maneira de se autodefender das agressões sofridas, expressa mais uma vez a mudança cultural, os valores sociais a caminho da igualdade e simetria. Como é o caso do artigo 06 que tem o sexo masculino como vitimizado.

E a violência bidirecional, ou seja, ambos são perpetradores, como o artigo 06 mostra, significa o fato de praticarem a violência ao mesmo tempo. Conforme Minayo et al (2011), crianças e adolescentes que vivem em uma família ou uma comunidade violenta precisam se constituir e aprender como se comunicar e como agir nas relações cotidianas que sempre exigem enfrentamento e tomada de decisões, para obter poder e amedrontar os outros. 


\section{Considerações Finais}

O presente trabalho expôs a situação de violência experimentada por parcela considerável de adolescentes em relações de namoro.A pesquisa possibilitou a constatação de que as causas da violência, nas relações entre namorados adolescentes, sofrem incontestável influência de vivências agressivas prévias, comumente, ligadas aos pais, aos irmãos, aos amigos e a relacionamentos anteriores. Depreende-se, por meio dos dados coletados nos artigos analisados no presente estudo, que não há concordância absoluta acerca da prevalência de gênero do agressor, contudo, todos os autores entendem que a violência reflete um padrão de continuidade do comportamento agressivo.

Embora ocorram diversas formas de violência (sexual, física, verbal, psicológica), verificou-se que, constantemente, todas estão intrinsicamente ligadas à violência de cunho psicológico. Tendo em vista a idade dos envolvidos, as repercussões do comportamento agressivo, o aumento no número de casos de violência nos namoros entre adolescentes, dentre outros fatores, mostrase imprescindível o prosseguimento de pesquisas relacionadas ao assunto, a fim de viabilizar uma melhor análise das condições propiciadoras de violência para, então, serem implantadas programas de prevenção que atendam, especificamente, às necessidades do grupo-alvo.

\section{Referências}

ABERASTURY, Arminda et al. Adolescência. Trad. por Ruth Cabral. Porto Alegre, Artes Médicas, 2. Ed. 1983, 246p, 22cm.

ABREU, Thales Oliveira; SOUZA, Marjane Bernardy. A Influência da Internet nos Adolescentes com Ações Suicidas. Revista Sociais e Humanas, [S.I.], v. 30, n. 1, jun. 2017. ISSN 2317-1758. Disponível em: <https://periodicos.ufsm.br/ sociaisehumanas/article/view/25868>. Acesso em: 13 set. 2017. doi:http://dx.doi. org/10.5902/2317175825868.

BARREIRA, A., LIMA, M., \& AVANCI, J. (2013). Coocorrência de violência física e psicológica entre adolescentes namorados do Recife, Brasil: Prevalência e fatores associados. Ciência e Saúde Coletiva, 18(1), 233-243. Recuperado de http://dx.doi.org/10.1590/S1413-81232013000100024

BARREIRA, A.; LIMA, M,; BIGRAS, M,; NAJAINE, K., ASSIS, S, G. Direcionalidade da Violência Física e Psicológica no Namoro entre Adolescentes do Recife, Brasil. Revista Brasileira de Epidemiologia. Vol. 17, n 1, São Paulo, Jan/Mar. 2014 Disponível em <http://dx.doi.org/10.1590/1415-790X201400010017ENG>.

BESERRA, M. A., LEITÃO, M. N. C., FERNANDES, M. I. D., SCATENA, L., VIDINHA, T. S. S., SILVA, L. M. P., FERRIANE, M. G. C. Prevalência de Violência no Namoro entre Adolescentes de Escolas Públicas de Recife/PE - Brasil. Disponível em: <http://dx.doi.org/10.12707/RIV15006>.

BESERRA, M. A., LEITÃO. M. N. C., FABIÃO. J. A. S. A. O., DIXE. M. A. C. R., VERÍSSIMO. C. M. F., FERRIANI. M. G. C., Prevalência e Características da Violência no 
A VIOLÊNCIA NAS RELAÇÕES AFETIVAS DE ADOLESCENTES: UMA REVISÃO SISTEMÁTICA

Namoro entre Adolescentes Escolares de Portugal. Esc. Anna Nery 2016; 20(1):183-191 DOI: 10.5935/1414-8145.20160024

Brancaglioni. B. C. A., Fonseca. R. M. G. S, Violência por Parceiro Íntimo na Adolescência: uma análise de gênero e geração. Rev. Bras. Enferm. Vol. 69 n5 Brasília Sept./Oct. 2016 http://dx.doi.org/10.1590/0034-7167-2016-0408

BRASIL, Ministério da Saúde. Impacto da violência na saúde dos brasileiros. Brasília: Ministério da Saúde; 2005. (Série B. Textos Básicos de Saúde).

BRASIL. Ministério da Saúde. Secretaria Executiva. Coordenação da Saúde da Criança e do Adolescente. Programa Saúde do Adolescente. Bases Programáticas. 2a Edição. Brasília; Ministério da Saúde, 1996. p. 32.

CAMARGO, Orson. "Violência no Brasil, outro olhar." Brasil Escola. Disponível em <http:// brasilescola.uol.com.br/sociologia//violencia-no-brasil.htm>. Acesso em 29.08.17.

CECCHETTO. Fátima, OLIVEIRA. Q. B. M, NJAINE.K, MINAYO. M. C. S. Violências Percebidas por Homens Adolescentes na Interação Afetivo - Sexual em dez cidades brasileiras. Interfase (Botucatu), vol.20, n59, Botucatu, Out./ Dez. 2016 Epub 28-Jun-2016. Disponível em:<http:/dx.doi.org/10.1590/180757622015.0082>. Acesso em 16-09-2017.

FÁVERO, M. H. (2010). Psicologia do Gênero: Psicobiografia, sociocultural e transformações. Curitiba: Editora UFPR.

Foshee, V., Reyes, H., Gottfredson. N., Chang. LY. \& Ennet, S. (2013). A longitudinal examination of psychological, behavioral, academic, and relationship consequences of dating abuse victimization among a primarily rural sample of adolescentes. Jounarl of adolescente Health, 53(6), 723-729. Doi:http:/dx.doi.org/10.1016/j.jadohealth.2013.06.016

LEITÃO, M. N. C. Violência nas Relações de Intimidade. Unidade de Investigação em Ciências da Saúde. Enfermagem Escola. Superior de Enfermagem de CoimbraPlano de Atividades. Coimbra: 2013, p.25-42

MINAYO, Maria Cecilia de Souza (org). Amor e violência: um paradoxo das relações de namoro e do "ficar" entre jovens brasileiros. / organizado por Maria Cecilia de Souza Minayo, Simone Gonçalves de Assis e Kathie Njaine. - Rio de Janeiro: Editora Fiocruz, 2011. 236p. ISBN: 978-857541-212-1

MOURA, Leides Barroso Azevedo; De Oliveira, Cesar; VASCONCELOS, Ana Maria Nogales. Violências e Juventude em um território da Área Metropolitana de Brasília, Brasília uma abordagem socioespacial. Revista Ciência \& Saúde Coletiva, v.20, n.11, 2015.

OLIVEIRA, Q. B. M, ASSIS S. G, NJAINE K, PIRES T. O. Namoro na adolescência no Brasil: Circularidade da Violência Psicológica nos diferentes contextos relacionais. Ciência Saúde Coletiva, 28/02/2013.

OLIVEIRA Q. B. M, ASSIS S. G, NJAINE K, Pires T. O. Violência Física Perpetrada por Ciúmes no Namoro de Adolescentes: Um recorte de Gênero em Dez Capitais Brasileiras. Disponível em:<www.scielo.br/pdf/ptp/v32n3/1806-3446ptp-e32323.pdf> Acesso em 16.09.17.

WAISELFISZ, J J. Mapa da Violência 2013: Homicídios e Juventude no Brasil. Rio de Janeiro; 2013.

WAISELFISZ, J J. Mapa da violência 2012: Crianças e Adolescentes do Brasil. Rio de Janeiro: Flacso Brasil; 2012. 